\title{
Impaired Lymphocyte Proliferative Response to Mitogen in Alcoholic Patients. Absence of a Relation to Liver Disease Activity
}

\author{
Milton G. Mutchnick, MD and Horchang H. Lee, MD
}

\begin{abstract}
Concanavalin A-induced lymphocyte proliferation was studied in $\mathbf{2 5}$ patients with alcoholic hepatitis or compensated alcoholic cirrhosis. Nine alcoholics without evidence of liver disease were also evaluated. A nonlinear correlation equation, which was natural logarithmic, was applied to individual dose-response proliferation curves and permitted comparisone between patient groups and controls. The proliferative responee in all patient groups was significantly lower when compared to healthy controls and was independent of the presence or absence of liver disease. This suggests that some changes in immune function observed in alcoholics may be linked to the direct effects of alcohol on the immune system rather than to the associated Itver disease.
\end{abstract}

$\mathbf{L}$ YMPHOPROLIFERATIVE RESPONSES to nonspecific mitogen stimulation have been employed to assess immunological function in healthy individuals as well as in patients with a variety of diseases. Mitogeninduced proliferation and, modulation of such reactivity, is subject to influence by multiple factors which would include the stimulating agent, the source and composition of the lymphocytes, culture conditions, and the immune status of the subject. ${ }^{1,2}$

Comparisons of lymphoproliferative responses between groups of disease-related patients and healthy subjects is difficult since the mitogen dose-response relationship is nonlinear. Most studies have used Student's $t$ test to compare differences between groups at each mitogen dosage, however considerable individual variation exists in the magnitude of the response. In other approaches the optimal response of peripheral blood mononuclear (PBM) cells to increasing concentrations of a single mitogen is related to the response of the same PBM to a second mitogen. ${ }^{3}$ Most frequently a single dose of mitogen is used which is derived from the peak proliferative response exhibited by control PBM.

Conflicting results have been reported on lymphocyte

From the Department of Internal Medicine, Division of Gastroenterology, Wayne State University School of Medicine, Detroit, MI, and the Veterans Administration Medical Center, Ann Arbor, MI.

Received for publication April 13, 1987; revised manuscript received July 1, 1987; accepted August 3, 1987.

Support for this research was received from the Veterans Administration and by an NIH Biomedical Research Support Grant (RR05083).

Reprint requests: Milton G. Mutchnick, Chief, Section of Gastroenterology, Hutzel Hospital, 4707 St. Antoine, Detroit, MI 48201.

Copyright (C) 1988 by The Research Society on Alcoholism. transformation assays in patients with alcoholic liver disease (ALD). Decreased proliferative responses to the mitogens phytohemagglutinin (PHA) and concanavalin (Con A) have been described in patients with alcoholic hepatitis $(\mathrm{AH})^{4-7}$ and in patients with compensated alcoholic cirrhosis (CAC) or fatty infiltration., ${ }^{4,7,8}$ However, normal proliferative responses have also been reported in patients with $\mathrm{AH},{ }^{9} \mathrm{CAC}$ or fatty infiltration. ${ }^{5,6,10}$ In a similar manner both decreased mitogen-induced proliferative responses ${ }^{11}$ and normal responses ${ }^{4,5,9}$ have been described in alcoholics without liver disease.

Recently a natural logarithmic relationship was described between mitogen stimulation and human lymphocyte response in a dose-response proliferation assay. ${ }^{12}$ Application of a nonlinear correlation equation to individual proliferation curves may permit quantitative comparisons between groups of patients and controls.

We measured the proliferative response to increasing doses of Con A by PBM isolated from alcoholic patients and from healthy volunteers. Comparisons of the responses were accomplished using a natural logarithmic relationship equation.

\section{PATIENTS AND METHODS}

\section{Study Groups}

Twenty-five patients with ALD were studied. Fourteen patients (nine males and five females) were considered to have $\mathrm{AH}$ on the basis of clinical and laboratory findings to include the following criteria after at least 5 days in the hospital: Recent alcohol consumption in excess of 1 pint of whiskey per day or its alcohol equivalent; hepatomegaly; a total serum bilirubin $\geq 4 \mathrm{mg} \%$; and abnormalities in at least two of the following parameters: (a) serum glutamic oxaloacetic transaminase (SGOT) more than $80 \mathrm{IU} / \mathrm{ml}$ (normal $<40 \mathrm{IU}$ ), (b) serum albumin $\leq 3$ $\mathrm{g} \%$, or (c) prothrombin time $\geq 2 \mathrm{sec}$ in excess of the control value. Coagulation deficiencies and/or the presence of ascites precluded percutaneous liver biopsy in all but four of these patients. In all cases where biopsy was accomplished, the clinical diagnosis of $\mathrm{AH}$ was confirmed by the presence of alcoholic hyalin, liver cell necrosis, and polymorphonuclear neutrophil infiltrate. Two of the biopsies revealed concomitant micronodular cirrhosis (Table 1).

Eleven alcoholic patients (eight males and three females) were diagnosed as having CAC following liver biopsy in which features of a superimposed hepatitis were not identified (Table 1).

Nine AWLD (all males) were studied to determine the influence of recent chronic alcohol ingestion on PBM function. These patients were selected from the inpatient alcohol rehabilitation service of the Ann Arbor Veterans Administration Medical Center. All patients were examined at least 7 days following admission and had ingested a minimum 
Table 1. Liver Function Profile of Patient Groups

\begin{tabular}{|c|c|c|c|c|c|c|}
\hline Group & Age (yrs) & $\begin{array}{l}\text { Total serum bilirubin } \\
\text { (mg/100 ml) }\end{array}$ & $\begin{array}{c}\text { Serum } \\
\text { alkaline phosphatase } \\
\text { (IU) }\end{array}$ & $\begin{array}{c}\text { SGOT } \\
\text { (IU) }\end{array}$ & $\begin{array}{l}\text { Serum albumin } \\
(\mathrm{g} / 100 \mathrm{ml})\end{array}$ & $\begin{array}{c}\text { Prothrombin } \\
\text { time prolongation } \\
\text { (s) }\end{array}$ \\
\hline $\mathrm{AH}^{*}$ & $39 \pm 3$ & $14.8 \pm 2.8$ & $244 \pm 23$ & $154 \pm 22$ & $2.4 \pm 0.1$ & $4.3 \pm 0.7$ \\
\hline CAC & $54 \pm 14$ & $1.3 \pm 0.3$ & $171 \pm 24$ & $52 \pm 17$ & $3.7 \pm 0.2$ & $0.8 \pm 0.3$ \\
\hline AWLD & $44 \pm 3$ & $0.4 \pm 0.1$ & $69 \pm 8$ & $42 \pm 13$ & $4.6 \pm 0.1$ & NDt \\
\hline
\end{tabular}

Values, means \pm SEM.

- AH, akcoholic hepatitis; CAC, compensated alcoholic cirrhosis; AWLD, alcoholics without liver disease.

† ND, not done.

of 1 pint of whiskey or its equivalent per day prior to admission. Laboratory studies showed normal or mild elevations in serum SGOT, total bilirubin, and alkaline phosphatase values. None of the patients had hepatomegaly or clinical findings to suggest acute or chronic liver disease. Liver biopsies were not obtained. Control subjects consisted of 51 healthy volunteers ( 39 males, 12 females; $32 \pm 2 \mathrm{yr}$ ) not known to abuse alcohol or to be using medication. This study was approved by the Ann Arbor Veterans Administration Medical Center Human Studies Committee.

\section{Isolation of $P B M$}

Freshly heparinized peripheral blood was drawn from patients and controls and PBM isolated using Ficoll-Hypaque gradient as previously described (13). Cells were resuspended in RPMI 1640 (GIBCO, Grand Island, NY) enriched with vitamins, $2 \mathrm{~mm}$ glutamine, penicillin (100 units $/ \mathrm{ml})$, streptomycin $(100 \mu \mathrm{g} / \mathrm{ml})$, and $10 \%$ heat-inactivated fetal calf serum (FCS; Hyclone, Sterile System, Inc., Logan, UT).

\section{Proliferation Assay}

PBM, $0.15 \mathrm{ml}\left(1 \times 10^{5}\right.$ cells $)$, were added to $0.05 \mathrm{ml}$ of increasing concentrations of Con A (Pharmacia Fine Chemicals, Piscataway, NJ) in wells of a round-bottom microtiter culture plate (Falcon Plastics, Oxnard, CA). The final concentrations of Con $A$ in the wells were 0,1 , $5,10,20$, and $40 \mu \mathrm{g} / \mathrm{ml}$. All experiments were performed in triplicate. The plates were incubated at $37^{\circ} \mathrm{C}$ for $72 \mathrm{~h}$ in a humidified $5 \% \mathrm{CO}_{2}$ and air atmosphere. Tritiated thymidine, $1 \mu \mathrm{Ci}$ (New England Nuclear, Waltham, MA), was added to each well $4 \mathrm{~h}$ prior to harvesting with an automatic multiple sample harvester (Otto Hiller Co., Madison, WI). The incorporation of $\left[{ }^{3} \mathrm{H}\right]$ thymidine was measured in a Beckman liquid scintillation system. PBM from control subjects were always included in assays in which alcoholic patients were studied.

\section{Statistical Analysis}

The proliferation ratio (PR) of each condition for each subject was determined using the equation, $P R=B+K_{\mathrm{p}} \ln [X]$, where $\ln =\log _{e}$, natural logarithm, $X=$ Con $A$ concentration, $B=$ basal $P R$, and $K_{\mathrm{p}}=$ proliferation coefficient.

A personal computer (PC) program using BASIC language as previously described $^{12}$ enabled complete data calculations to obtain $K_{\mathrm{p}}, B$, and $r$ correlation coefficient values from the input of each Con A dose and the response in cpm. Comparisons of discrete variables between patient groups and controls were by Student's $t$ test.

\section{RESULTS}

To assess for possible age-related differences in the proliferative responses of the control group, ${ }^{14}$ the healthy volunteers were divided into two age groups: $20-40$ years and 41-60 years. As shown in Table 2, there were no significant differences between the two age groups or between the two groups and the total control group in either the cpm at each Con A concentration or in the $K_{\mathrm{p}}$ values.

Significant differences in cpm were noted at several Con A concentrations when comparing the $\mathrm{AH}$ and $\mathrm{CAC}$ responses to those of the controls. A consistent decrease in proliferative response was seen in the AWLD at all mitogenic concentrations of Con A (Table 3). Although the three patient groups (AH, CAC, and AWLD) had significantly lower $K_{\mathrm{p}}$ values than the control group, all study groups displayed highly significant natural logarithmic correlations when comparing proliferation ratios and each concentration of Con $\mathrm{A}$ in the proliferation assay (Table 4).

\section{DISCUSSION}

The $K_{\mathrm{p}}$ values observed for the AH, CAC, and AWLD groups confirm that there is a decrease in lymphocyte proliferative responses to mitogen stimulation in these patients. Our results, in part, also provide an explanation for the conflicting observations which have previously been reported in alcoholic patients. Most studies have utilized a single concentration of PHA or pokeweed

Table 2. Age-related Comparisons of Proliferative Response and Proliferation Coefficient in Controls

\begin{tabular}{|c|c|c|c|c|c|}
\hline Con A $(\mu g / m l)$ & $\begin{array}{c}\text { Total control group } \\
(51)^{*}\end{array}$ & $\begin{array}{c}\text { Controls, } \\
20-40 \text { years } \\
(38)\end{array}$ & $p$ & $\begin{array}{c}\text { Controls, } \\
41-60 \text { years } \\
\text { (13) }\end{array}$ & $p$ \\
\hline 0 & $533 \pm 55 t$ & $498 \pm 54$ & NS $\ddagger$ & $636 \pm 142$ & NS \\
\hline 1 & $2200 \pm 450$ & $2077 \pm 396$ & NS & $2560 \pm 1326$ & NS \\
\hline 5 & $6144 \pm 869$ & $6174 \pm 981$ & NS & $6057 \pm 1843$ & NS \\
\hline 10 & $10231 \pm 1030$ & $10467 \pm 1139$ & NS & $9540 \pm 2276$ & NS \\
\hline 20 & $13711 \pm 1327$ & $14703 \pm 1513$ & NS & $10811 \pm 2586$ & NS \\
\hline 40 & $15757 \pm 1394$ & $16721 \pm 1609$ & NS & $12942 \pm 2640$ & NS \\
\hline$K_{p} \S$ & $12.58 \pm 2.68$ & $11.46 \pm 1.86$ & NS & $15.86 \pm 8.93$ & NS \\
\hline
\end{tabular}

- Numbers in parentheses, number of subjects tested.

† Mean cpm \pm SEM $/ 10^{5}$ PBM.

$\mp$ NS, not significant compared to total control group and alternate age-control group.

$\S K_{p}$, coefficient of natural logarithmic difference in proliferation for each Con A condition. 
Table 3. Con A Induced Proliferative Response in Alcoholic Patients

\begin{tabular}{|c|c|c|c|c|c|c|c|}
\hline $\operatorname{Con} A(\mu \mathrm{g} / \mathrm{ml})$ & Controls $(51)^{\star}$ & $\mathrm{AH}+(14)$ & $\rho \ddagger$ & CAC (11) & $\rho$ & AWLD (9) & $p$ \\
\hline 0 & $533 \pm 55 \S$ & $1287 \pm 378$ & & $586 \pm 85$ & & $665 \pm 101$ & \\
\hline 1 & $2200 \pm 450$ & $2820 \pm 556$ & & $1557 \pm 314$ & & $1681 \pm 224$ & \\
\hline 5 & $6144 \pm 869$ & $5982 \pm 1086$ & & $3212 \pm 469$ & $<0.01$ & $4049 \pm 343$ & $<0.05$ \\
\hline 10 & $10231 \pm 1030$ & $7085 \pm 1018$ & $<0.05$ & $9706 \pm 4945$ & & $6797 \pm 778$ & $<0.01$ \\
\hline 20 & $13711 \pm 1327$ & $9416 \pm 1525$ & $<0.05$ & $6932 \pm 790$ & $<0.01$ & $9051 \pm 1215$ & $<0.01$ \\
\hline 40 & $15757 \pm 1394$ & $11632 \pm 2087$ & & $11299 \pm 2808$ & & $9597 \pm 635$ & $<0.01$ \\
\hline
\end{tabular}

" Numbers in parentheses, number of subjects tested.

† AH, alcoholic hepatitis; CAC, compensated alcoholic cirrhosis; AWLD, alcoholics without liver disease.

$\ddagger \rho$ values, compared to controls, Student's $t$ test.

\$ Mean $\mathrm{cpm} \pm \mathrm{SEM} / 10^{5} \mathrm{PBM}$.

Table 4. Statistical Significance of the Proliferation Equation among Groups

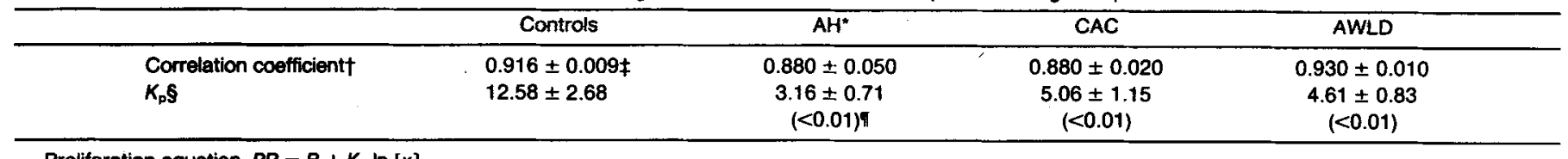

Protiferation equation, $P R=B+K_{\mathrm{p}} \ln [x]$.

- AH, alcoholic hepatitis; CAC, compensated alcoholic cirrhosis; AWLD, alcoholics without liver disease.

+ Correlation coefficient $(r)$ of the proliferation equation.

$\ddagger$ Means \pm sEM.

$\S K_{p}$, coefficient of natural logarithmic difference in proliferation for each Con A condition.

I $p$ value, Student's $t$ test when $K_{\mathrm{p}}$ is compared to control value.

mitogen $^{4-6,8,10}$ while two studies examined the proliferative responses to two concentrations each, of PHA and Con A. $^{7,9}$ In all, statistical analyses were accomplished using the data obtained at discrete mitogen dosages and in none were dose-response proliferation curves obtained. In one investigation, ${ }^{9}$ the concentrations of PHA and Con A used were determined by dose-response curves in healthy subjects yielding maximum transformation responses. Previous work has shown however, that multiple doses of a mitogen are required since abnormalities in lymphocyte response may occur only at suboptimal doses. ${ }^{15,16}$

The Con A proliferation curve employed in the present study demonstrates a variable response to the different concentrations of the mitogen (Table 3). Selection of a single Con A dose of $40 \mu \mathrm{g} / \mathrm{ml}$ would have resulted in the impression that PBM from patients with $\mathrm{AH}$ and CAC undergo normal proliferative responses. Determination of $K_{\mathrm{p}}$ values in lymphocyte transformation assays would appear to provide a more reliable approach towards the detection of decreased cell-mediated immune function. ${ }^{12}$

The natural logarithmic equation has been used in a number of biological conditions where dose-response relationships are not linear. ${ }^{12,17,18}$ In a similar manner, proliferation assays exhibit a decay in the growth rate as the concentrations of the mitogen are increased. ${ }^{19,20} \mathrm{Al}-$ though PBM from alcoholic patients are capable of responding to mitogen stimulation, with the In correlation in cellular proliferation remaining intact (Table 4), the proliferation coefficient is significantly decreased when compared to healthy controls.

The literature is replete with descriptions of multiple immunological abnormalities associated with chronic alcohol abuse in the presence or absence of liver disease (reviewed in Ref. 21), however there is as yet no conclusive evidence to support a pathogenetic role for the host immune response in ALD.

This study provides further indication that the transformation responses in alcoholic patients may not be related to liver disease activity. Although there was no clinical indication of malnutrition in the CAC and AWLD patients reported in this study, we cannot exclude the possibility that subtle changes in nutritional status may have influenced the proliferative response to mitogens in the patient groups. $^{6}$

The decreased proliferative response to Con A by alcoholic patients reflects a probable perturbation in cellmediated immunity and an immune deficiency state. ${ }^{2}$ Application of a natural logarithmic equation to a doseresponse mitogen driven proliferation assay permits a more precise quantitative comparison of immunological function between patient groups and healthy volunteers.

\section{REFERENCES}

1. Alford RH: Metal cation requirements for phytohemagglutinininduced transformation of human peripheral blood lymphocytes. J Immunol 104:698-703, 1970

2. Oppenheim JJ, Schecter B: Lymphocyte transformation, in Rose NR, Friedman H (eds): Manual of Clinical Immunology. Washington DC, American Society Microbiology, 1976, p 81

3. Cunningham-Rundles S, Hansen JA, Dupon B: Lymphocyte transformation in vitro in response to mitogens and antigens, in Bach FH, Good RA (eds): Clinical Immunology. New York, Academic Press, 1976, p 151

4. Chen T, Leevy CM: Lymphocyte proliferation inhibitory factor (PIF) in alcoholic liver disease. Clin Exp Immunol 26:42-45, 1976

5. Sorrell MF, Leevy CM: Lymphocyte transformation and alcoholic liver injury. Gastroenterology 63:1020-1025, 1972

6. Zetterman RK, Leevy CM: Immunologic reactivity and alcoholic liver disease. Bull NY Acad Med 51:533-544, 1975

7. Snyder N, Bessoff J, Dwyer JM, Conn HO: Depressed delayed cutaneous hypersensitivity in alcoholic hepatitis. Dig Dis Sci 23:353357,1978

8. Thestrup-Pedersen K, Ladefoged K, Andersen P: Lymphocyte 
transformation test with liver-specific protein and phytohaemagglutinin in patients with liver disease. Clin Exp Immunol 24:1-8, 1976

9. Watson RR, Jackson JC, Hartmann B, Sampliner R, Mobley D, Eskelson C: Cellular immune functions, endorphins, and alcohol consumption in males. Alcohol Clin Exp Res 9:248-254, 1985

10. Hsu CCS, Leevy CM: Inhibition of PHA-stimulated lymphocyte transformation by plasma from patients with advanced alcoholic cirrhosis. Clin Exp Immunol 8:749-760, 1971

11. Lundy J, Raaf JH, Deakins S, Wanebo HJ, Jacobs DA, Lee T-d, Jacobowitz D, Spear C, Oettgen HF: The acute and chronic effects of alcohol on the human immune system. Surg Gyn Obstet 141:212-218, 1975

12. Lee HH, Mutchnick MG: Quantitative analysis of mitogen-stimulated cellular proliferation: Effect of concanavalin A and thymosin interaction. Int J Bio Med Comp 20:265-273, 1987

13. Boyum A: Separation of leukocytes from blood and bone marrow. Scand J Clin Lab Invest 21:31-50, 1968

14. Foad BSI, Adams LE, Yamauchi Y, Litwin A: Phytomitogen responses of peripheral blood lymphocytes in young and older subjects. Clin Exp Immunol 17:657-664, 1974
15. Ziegler JB, Hansen $\mathbf{P}$, Penny R: Intrinsic lymphocyte defect in Hodgkin's disease: analysis of the phytohemagglutinin dose response. Clin Immunol Immunopathol 3:451-460, 1975

16. Oppenheim JJ, Blaese RM, Waldmann TA: Impaired lymphocyte transformation and delayed hypersensitivity in Wiskott Aldrich syndrome. J Immunol 104:835-844, 1970

17. Ledley RS: Use of Computers in Biology and Medicine. New York, McGraw-Hill Co., 1965

18. Edler L, Wahrendorf J, Frank N: Computational methods for the screening of pharmacokinetic parameters in metabolism experiments. Int J Bio-Med Comput 14:369-380, 1983

19. Cherrault Y, Savin VB: General treatment of linear mammillary models. Int J Bio-Med Comput 16:119-126, 1985

20. Faguet GB: Mechanisms of lymphocyte activation. Binding kinetics of phytohemagglutinin to human lymphocytes. J Biol Chem 232:2095-2100, 1977

21. Johnson RD, Williams R: Immune responses in alcoholic liver disease. Alcohol Clin Exp Res 10:471-486, 1986 